was found to contain a large number of cartilage cells with a more or less homogeneous matrix.

The patient resumed work about six weeks after the operation. When seen in September last the bone was found to have diminished slightly in size. He had had no pain or inconvenience in it, and the movement at the joint was easy and free to the extent of a right angle.

Queen Anne-street, W.

\section{NOTE ON A CASE OF IMMEDIATE SERUM REACTION.}

By T. Thomson Rankin, M.D. GlasG., AND

A. M. Pryce, Mi.B., Ch.B. Edin., ASSTSTANT MEDICAL OFIICERS, GITY HOSPITALS, LEEDS.

THE following case is of interest in so far as it shows an immediate reaction to a single dose of anti-diphtheritic serum.

A female infant, aged 21 months, was admitted to the Leeds City Hospitals on July 5th, 1910, suffering from diphtheria. On admission she received 5000 units of concentrated diphtheria antitoxin (P. D. and Co.) by subcutaneous abdominal injection. Within 15 minutes a profuse and typical urticarial eruption appeared on the face, arms, back, chest, and legs. This rash lasted two days and disappeared gradually; the highest temperature noted during its presence was $101.4 \circ \mathrm{F}$. On the eleventh day of the disease and the seventh after the injection another urticarial eruption dereloped and the temperature did not exceed 1000. The patient did well and was discharged on August 24th. Prior to her discharge 2 c.c. of sterile water were injected subcutaneously without any reaction being made manifest.

The occurrence of immediate and accelerated reactions following repeated injections of anti-diphtheritic serum has been noted and recorded, but the appearance of serum phenomena so soon after a single injection has not come under our notice. To avoid the possibility of error, we injected the sterile water and inquired into the history of the child and mother. The failure of the sterile water to produce any reaction is evidence of the fact that the phenomena were due to the serum. We were able on close inquiry to ex. clude the usual causes of urticaria, such as unsuitable diet, drugs, \&c.

It has been suggested that a woman who has had diphtheria antitoxin may transmit to her child a tendency to be abnormally sensitive to serum, as occurs in the case of guinea-pigs. We are able to exclude this possibility, as the mother of the child never had diphtheria or diphtheria antitoxin.

We are indebted to Dr. A. E. Pearson for his kind permission to publish these notes.

Leeds.

\section{NOTE ON A CASE OF MUCOUS COLITIS SUCCESS- FULLY TREATED BY VACCINE-THERAPY.}

By G. C. Stefle-Perkins, M.D. Edin., M.R.C.S. EnG., L.R.C.P LOND.

A FEMALE, aged 23 years, came to me on Oct. 1st, 1909, with a history of mucous colitis on and off (diagnosed as such by her medical attendants) for the past eight years. The present attack commenced six months ago. Her symptoms were loose motions, the passing of mucus and shreds of membrane, straining at stool, constipation, and pain and tenderness in the region of the ascending, but especially in the region of the descending, colon. She was feeling quite unfit to do anything, became easily tired, and was generally out of health.

Until Feb. 28th, 1910, I tried a variety of treatment, including rest, dieting, decoction of cortex simarubx, massage of the colon, \&c., but the patient showed no improvement. On the above date I sent specimens of her blood, urine, and fæces to Dr. J. W. H. Eyre for bacteriological examination, who on March 3rd reported as follows : "Urine: sterile. Fæces show that the normal bacillus coll is practically absent, but its place has been taken by streptococcus pyogenes longus and a bacillus having characters intermediate between the bacillus lactis aerogenes and bacillus pneumoniæ of Friedländer. Blood: Opsonic index to the streptococcus 0.7 , and to the bacillus 0.6 ." Vaccines were prepared from each of these micro-organisms. From March 7th to May 31st I injected the patient with the prepared vaccines of both the streptococcus and bacillus, in doses from 5 millions to 25 millions, at intervals of about eight days.

The details of these injections and of the opsonic indices are as follows:-On March 7th and 14th, 5 millions each of the streptococcus and bacillus. March 18th: Opsonic index to streptococcus $1 \cdot 3$, to bacillus $0 \cdot 9$. 21st: 10 millions of the bacillus. 29th : 10 millions each of the streptococcus and bacillus. April 6th: Opsonic index to streptococcus 1.01 , to bacillus 0.8 . 7th : 10 millions each of the streptococcus and bacillus. 15th : Opsonic index to streptococcus $1 \cdot 1$, to bacillus 0.5 . 16th : Streptococcus 10 millions. 20th : Bacillus 10 millions 27th : Opsonic index to streptococcus $1 \cdot 09$, to bacillus 1.1. 28th, May 6th and 14th: Streptococcus 10 millions and bacillus 25 millions. May 18th: Opsonic index to streptococcus $1 \cdot 0$, to bacillus $1 \cdot 2$. 23rd and 31st: Streptococcus 25 millions, and bacillus 25 millions. On May 31st the patient told me she had not suffered severe pain for over six weeks, that she was considerably better in health, and was passing a much less number of shreds; there was no tenderness of abdomen. Dr. Eyre reported: "No streptococci in shreds from bowel."

From June 8th to Sept. 13th I injected the patient with the bacillus vaccine in doses from 25 to 50 millions at intervals of about a fortnight, and on the latter date the patient informed me that she had been feeling very well for several weeks. The details of these injections and of the opsonic indices are as follows:- June 8th: Bacillus 25 millions. 14th: Opsonic index to streptococcus 1.1, to bacillus 0.96 . 25th, July 9 th and 23rd: Bacillus 50 millions. July 28th : Opsonic index to streptococcus $1 \cdot 6$, to bacillus 1.2. August 5th, 22nd, and Sept. 2nd : Bacillus 50 millions. Sept. 7th: Opsonic index to bacillus 1.04. 13th: Bacillus 50 millions.

On Oct. 11th Dr. Epre reported: "The specimens of fæces show a practically normal bacteriological flora. The normal bacillus coli was present in what I should consider normal numbers. The bacillus from which the vaccine was prepared has entirely disappeared, and so also has the streptococcus longus. A few colonies of streptococcus brevis (a normal inhabitant of the intestinal tract) were noted."

During the vaccine treatment the patient continued having careful massage of the colon, was dieted, and non-irritating aperients were given when necessary. The doses of the vaccine were regulated partly by the clinical symptoms and partly by opsonic estimations of the blood.

Oct. 12th: The patient continues in good health, feels quite well, and passes no shreds of mucous membrane.

Wimpole-street, $W$.

British Dental Association.-The annual meeting of the metropolitan branch of the British Dental Association was held in the school buildings of St. Bartholomew's Hospital on the evening of Dec. 7th, Mr. W. B. Paterson, dental surgeon to the hospital and president of the branch, in the chair. After the transaction of formal business, Mr. Paterson delivered an address, in the course of which he described the origin and growth of the dental department of the hospital, the scope of its work as a charity, and its teaching in the medical school. The department was founded in 1837, when Mr. Arnold Rogers was appointed the first dental surgeon, with the duty of visiting the hospital one day in the week. Upon his retirement in 1849 he was succeeded by Mr. Tracy, who in turn was followed by $\mathrm{Mr}$. Alfred Coleman. In 1879 the department was reconstituted and met twice weekly. The department was now in charge of four dental officers and met daily. The dental teaching of medical students was carried out on definite lines, and quarterly classes were held for those about to commence surgical dressing in the wards. The elements of dental surgery were taught, and extraction operations practised in the dissecting rooms. Attendance at the casualty dental department and dressership in the department were open and free to all students, and were specially recommended to those who intended joining the Naval and Army Medical Services. After the address the members visited the great hall of the hospital, the new pathological block, and museum. The proceedings terminated with a conversazione in the library. 